\title{
ПРИОРИТЕТЫ СТУДЕНЧЕСТВА В ОТНОШЕНИИ КАЧЕСТВА ЖИЗНИ
}

\author{
Винокурова Н.А., Гудович И.С.
}

Работа посвящена анализу результатов социологического обследования вузовской молодежи относительно ее представлений о качестве жизни и о важности его различных характеристик. Приводится сравнительный анализ результатов ответов студентов города Москвы и Воронежа.

DOI: $10.20537 /$ mce2019econ10

Введение. В настоящее время особое место в социальноэкономическом дискурсе занимают вопросы, связанные с качеством жизни. Качество жизни находится в центре исследований, проведенных экономистами, социологами, психологами, специалистами в сфере управления образованием и представителями других научных областей, чьи интересы связаны с анализом ценностных ориентаций населения в условиях современной России. Анализируются запросы, представления и предпочтения людей разных возрастов относительно качества жизни как базовой ценностной ориентации. Исследователи отмечают, что «...в период социально-экономических изменений в российском обществе наблюдалась общая динамика возрастания значимости прагматических ценностей для личности, достижения успеха делового и в личной жизни, материального благосостояния» [1].

В последние 2 года задачи, связанные с улучшением качества жизни, выходят на общегосударственный уровень и превращаются в проблемы социально-политические. О них говорили президент В.В. Путин в Программе развития России с 2018 до 2024 г., а также в ежегодном послании Федеральному Собранию 2019 года, в котором представлены конкретные меры по улучшению качества жизни народонаселения нашей страны.

Представленная работа является продолжением ряда исследований, проведенных на материалах социологического опроса 2017 г. студентов (680 человек) ведущих вузов города Воронежа и нескольких ву- 
зов Москвы. В анкеты включены, главным образом, вопросы, которые не затрагивались другими исследователями молодежных проблем.

Основные результаты анализа полученных данных представлены в работах [2] и [3]. Одним из важных выводов, сделанных в этих работах, было то, что студенты имеют склонность к гедонизму. Это проявляется, в частности, в том, что основным приоритетом молодежи, который в будущем может влиять на выбор поведенческой модели, является высокое качество жизни. Качество жизни в данном случае рассматривается как субъективная характеристика того, какие материальные, социальные или культурные потребности студенты хотели бы удовлетворить в первую очередь.

Методология исследования. В настоящей работе мы исходим из предположения, принятого в современной психологии [4], что молодые люди студенческого возраста имеют осознанные ценностные ориентации, что они хорошо понимают, что для них действительно важно. Именно это позволяет изучать ценностные ориентации с помощью социологического обследования.

Долгое время в оценках качества жизни преобладал «объективистский» подход, когда интерес исследователей сосредотачивался на изучении объективных (чаще всего количественных) показателей, характеризующих качество жизни отдельных социальных групп, регионов, стран. При этом важность различных характеристик качества жизни для индивидуума определялась с помощью экспертных оценок. В последние годы «субъективистский» подход стал не менее важным. С помощью социологических опросов выясняется удовлетворенность людей теми или иными характеристиками качества жизни. Другой тип субъективистских исследований, широко принятый на вооружение учеными Запада, - это выяснение также с помощью анкетных опросов мнения респондентов о важности для них тех или иных характеристик качества жизни, что позволяет вместо экспертных оценок использовать в объективистских исследованиях оценки, сделанные самим человеком.

В представленной работе используется как раз такой субъективистский подход. Она посвящена анализу результатов социологического обследования студентов на предмет их представлений о качестве жизни, и о сравнительной важности его различных характеристик. При этом нас интересовало их мнение о важности таких характеристик для населения в целом (с точки зрения студентов), для них лично в настоящее время и предположительных оценок того, что может быть для них важно в будущем (через 10 лет). Было выбрано условно 14 характеристик качества 
жизни. Критерием выбора послужила возможность в дальнейшем сопоставлять их вербальные приоритеты с реальными объективными оценками, то есть использовать их как веса при объективных исследованиях. В анкету были включены наиболее репрезентативные, на наш взгляд, характеристики качества жизни. Прямой описательный метод представления результатов дополнялся аналитикой. Особую ценность представляют интервью, проведенные авторами на предмет выяснения критериев, по которым студенты оценивали компоненты качества жизни.

Особенностью нашего подхода является включение в рассмотрение нескольких вопросов на одну тему, но поставленных в разной форме или отражающих разные аспекты темы, с целью получения более адекватного результата.

Результаты. Прежде всего, нас интересовало, какие характеристики качества жизни студенты считают наиболее важными для них в настоящее время. Сравнительная оценка значимости шести из 14 наименований, признанных студентами наиболее важными в настоящее время, показана на рис. 1.

$$
\begin{array}{lllllllll}
0 & 10 & 20 & 30 & 40 & 50 & 60 & 70 & 80
\end{array}
$$

Возможность регулярно посещать фитнес-центр, бассейн и т.п.

Возможность оплачивать дополнительное образование

Возможность одеваться в фирменные вещи

Возможность ежегодно бывать в туристических поездках за рубежом

Наличие собственной квартиры

Возможность покупать качественные продукты питания

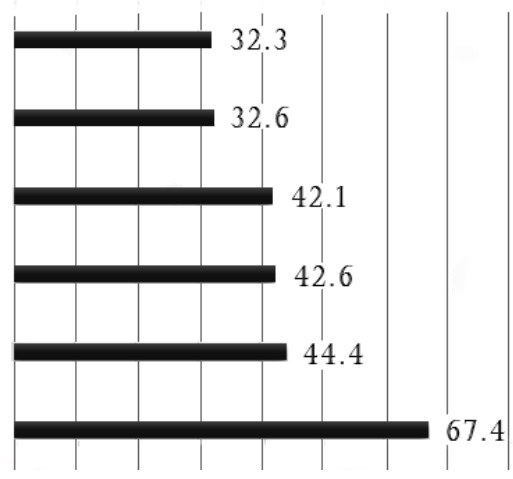

Рис. 1. Оценка значимости шести наиболее важных характеристик качества жизни для студентов Воронежа в настоящее время (процент ответов).

Наиболее значимой характеристикой качества жизни для текущего момента времени была признана возможность покупать качественные продукты. С большим отрывом было отмечено наличие собственной 
квартиры. Это свидетельство и более общей тенденции - стремления к свободе и независимости в широком смысле, и результат влияния западных представлений об образе жизни молодежи. Нужно отметить, что молодые люди высоко ценят ежегодную возможность ездить в туристические поездки за рубеж. Поездки за рубеж становятся определенным индикатором качества жизни, некоей символической характеристикой успешности. Однако возможность одеваться в фирменные вещи имеют по-прежнему высокий престиж у молодежи, соперничая с туристическими поездками за рубеж. Хотя в соответствии с данными Фонда «Общественное мнение» (ФОМ) [5] право на бесплатное образование и медицину является приоритетным для всего населения, и в том числе для молодежи, мы видим, что студенты уже ориентированы на платные услуги. Это касается и оплаты дополнительного образования, и получения спортивно-оздоровительных и медицинских услуг (см. табл. 1).

Таблица 1.Оценки значимости характеристик качества жизни второй по важности группы (процент ответов студентов г. Воронежа).

\begin{tabular}{|l|c|}
\hline $\begin{array}{l}\text { Возможность покупать хорошую компьютерную тех- } \\
\text { нику, телефоны и т.п. }\end{array}$ & 31.6 \\
\hline Возможность регулярно посещать театры и концерты & 30.1 \\
\hline $\begin{array}{l}\text { Возможность пользоваться платными медицинскими } \\
\text { услугами }\end{array}$ & 30.1 \\
\hline $\begin{array}{l}\text { Возможность помогать материально родным или } \\
\text { друзьям }\end{array}$ & 29.6 \\
\hline Возможность регулярно посещать кафе, бары и т.п. & 26.1 \\
\hline Наличие автомобиля & 25.8 \\
\hline Наличие банковского вклада & 11.0 \\
\hline Наличие загородного дома & 7.5 \\
\hline
\end{tabular}

Ко второй по значимости группе относится возможность покупать хорошую компьютерную технику. Важны для студентов и возможности проведения досуга. То, что на последнем месте оказалось наличие банковского вклада не удивительно: студенты не склонны к накоплениям не только потому, что у них не было такой возможности, но и потому, что они живут скорее сегодняшним днем. Следует отметить, что почти треть студентов считают важным для себя возможность помогать близким и друзьям, что свидетельствует об определенном чувстве гражданской ответственности. 
Наличие загородного дома

Наличие автомобиля

Наличие банковского вклада

Возможность помогать материально родным и друзьям

Наличие собственной квартиры

Возможность пользоваться платными медицинскими услугами

\section{8}

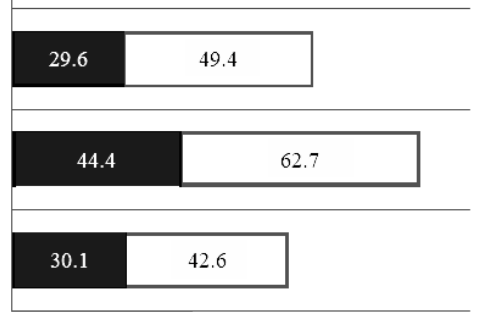

- Сегодня $\square$ Через 10 лет

Рис. 2. Представления студентов о важности для них характеристик качества жизни в настоящее время и через 10 лет (процент ответов).

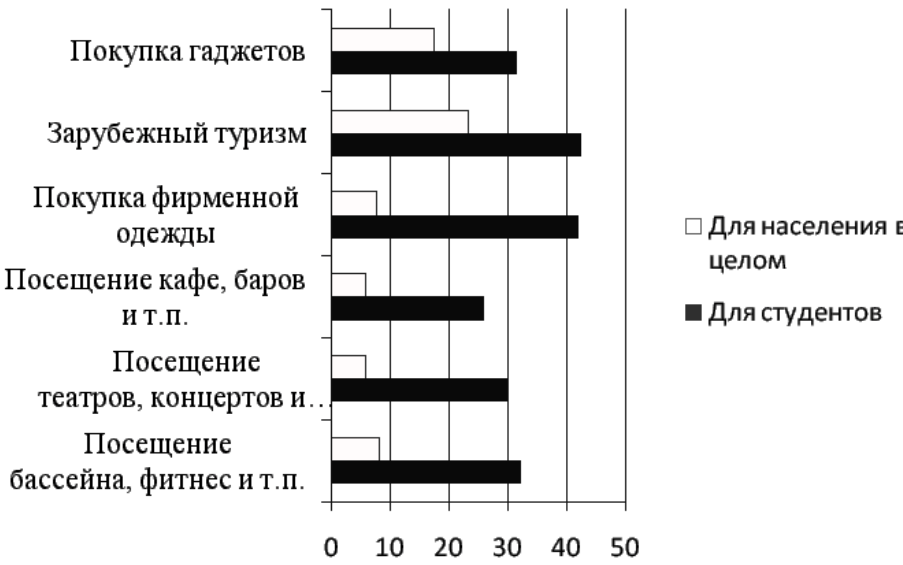

Рис. 3. Различия в оценке важности факторов, определяющих качество жизни, для молодежи и для населения в целом (процент ответов). 
Ситуация с тем, что студенты считают для себя важным, заметно меняется, когда речь идет о том, что они считали бы важным для себя через 10 лет. Вопрос заставил их задуматься о будущем. Как уже отмечалось в [1] и [2], студенты несколько инфантильны. Они полагают, что через 10 лет, к 30 годам у них будет меньше желания ходить в кафе, заниматься в фитнес-центрах, покупать хорошую одежду. Однако возрастет актуальность желания иметь собственную квартиру, загородный дом и автомобиль, а также возможности помогать родным (см. рис. 2).

Значительная разница в оценках студентами важности факторов, определяющих качество жизни, наблюдается, когда они говорят о предпочтениях населения в целом и с точки зрения собственной жизни (см. рис. 3).

Авторам настоящей работы казалось, что полученные результаты должны отличаться от результатов анализа обследования, проводимых в мегаполисах России. Однако, сравнение данных по шести характеристикам, отмеченным студентами Воронежа как наиболее важные, с результатами, полученными при обследовании московских студентов, принципиальной разницы в их взглядах не показало (см. табл. 2). Следует отметить лишь более высокий запрос на туристические поездки за границу у студентов Москвы и относительно большее количество студентов Воронежа, которые озабочены возможностью покупать качественные продукты питания.

Таблица 2. Оценка значимости шести наиболее важных характеристик качества жизни для студентов Москвы (процент ответов).

\begin{tabular}{|l|c|c|}
\hline \multicolumn{1}{|c|}{ Варианты ответов } & \multicolumn{2}{|c|}{ Процент ответов } \\
\cline { 2 - 3 } & Сегодня & Через 10 лет \\
\hline Возможность одеваться в фирменные вещи & 39.1 & 21.8 \\
\hline $\begin{array}{l}\text { Возможность регулярно посещать фитнес- } \\
\text { центр, бассейн и т. п. }\end{array}$ & 27.3 & 16.4 \\
\hline $\begin{array}{l}\text { Возможность ежегодно бывать в туристи- } \\
\text { ческих поездках за рубежом }\end{array}$ & 51.8 & 45.4 \\
\hline $\begin{array}{l}\text { Возможность покупать качественные про- } \\
\text { дукты питания }\end{array}$ & 60.9 & 52.7 \\
\hline $\begin{array}{l}\text { Возможность оплачивать дополнительное } \\
\text { образование }\end{array}$ & 37.3 & 20.9 \\
\hline Наличие собственной квартиры & 46.4 & 60.9 \\
\hline
\end{tabular}


Заключение. В результате проведенного исследования была выявлена устойчивость предпочтений молодежи для особой группы из набора сравниваемых в исследовании характеристик качества жизни, отличающихся по горизонту оценки, что свидетельствует об их фундаментальном характере. К ней относятся: наличие собственной квартиры, возможность ежегодно бывать в зарубежных туристических поездках и возможность покупать качественные продукты питания. Было установлено, что студенты очень чутко улавливают западные тенденции в потреблении и образе жизни и находятся под их влиянием, хотя традиционная ценность материальной поддержки родных и друзей тоже остается актуальной. Было показано, что различия между тем, что студенты считают важным для себя, и тем, что они полагают важным для всего населения, довольно значительны. Их настрой гедонистический: такие характеристики как развлечения, спорт, хорошая одежда представляются студентам гораздо менее важными для населения в целом, чем для них самих. Полученные результаты согласуются с данными, приведенными в Е.Ю. Красовой в [6]: «Ценности независимости и материальной обеспеченности, гедонизма и бытовой устроенности выделили почти $60 \%$ студенческой молодежи. Вместе с тем, семья и интеллектуальное развитие важны для 36\% опрошенных». Следует отметить, что принципиальной разницы в предпочтениях московских и воронежских студентов обнаружено не было.

\section{СПИСОК ЛИТЕРАТУРЫ}

1. Журавлева Н.А. Ценностные ориентации личности в изменяющемся российском обществе. // Психол. журн.. 2012. Т.33, №1 . с.30-39.

2. Винокурова Н.А., Гудович И. С., Баклыков А.С. Молодежь как стратегический ресурс будущего развития: ценностные ориентации, планы, мечты // Современная экономика: проблемы и решения. 2017. № 9 (93). с.14-31.

3. Баклыков А.С., Гудович И.С., Винокурова Н.А. Ценностные ориентации молодежи как фактор будущего развития // Системное моделирование социально-экономических процессов. Труды 40-й Юбилейной международной научной школы-семинара имени. акад. С.С.Шаталина, г. Воронеж, 1-7 октября 2017 г. Воронеж: Изд-во «Истоки», 2017. с.318-321. 
4. Леонтьев Д.А. Ценностные представления в индивидуальном и групповом сознании: виды, детерминанты и изменения во времени // Психологическое обозрение. 1998. № 1. с.13-25.

5. Гражданские права и свободы. Исследования ФОМ. URL: http://fom.ru/TSennosti/14053.

6. Красова Е.Ю. Роль видеорекламы в формировании ценностей студентов (опыт исследования в г. Воронеже) // Государство и общество в современной политике: сб. науч. статей. Вып.5. Воронеж: Научная книга, 2018. c.169-175.

\section{PRIORITIES OF STUDENTS WITH RESPECT TO THE QUALITY OF LIFE}

\section{Vinokurova N.A., Gudovich I.S.}

The work is devoted to the analysis of the sociological survey results of university young people regarding their ideas about the quality of life, and about the relative importance of its various characteristics. A comparative analysis of the students answers results of Moscow and Voronezh is given. 